\title{
Answering negative questions in Russian
}

Yulia Panchenko

Department of Theoretical and Applied Linguistics, Lomonosov Moscow State University, Russia

https://doi.org/10.36505/ExLing-2020/11/0038/000453

\begin{abstract}
In colloquial Russian answers "yes" and "no" to negative polar questions can either stand for confirmation or contradiction of the proposition of a question. This paper contains an experimental research of correlation between the choice of "yes" or "no" response particle and the way of expressing negation and the presence of $l i$ particle in a question and also of comprehension of the short "yes" answer. The results showed that there are several competing strategies for answering negative polar questions and acceptability judgments of possible answers in Russian, meanwhile the correlation with the presence of li particle in a question was approved.
\end{abstract}

Keywords: acceptability judgment task, negation, polar questions, yes/no answers, Russian

\section{Introduction}

Previous researches have shown that sentences which are both interrogative and negative are the most difficult to process, analyse and interpret (Savin, Perchonock 1965). Depending on the language negative polar questions (NPQ) may differ from positive polar questions (PPQ) by the response system (Evgrafova 1984), felicity conditions (Roelofsen et al. 2012) and ambiguity (Ladd 1981; Büring, Gungloson 2000; van Rooij, Šafářová 2003; Romero, Han 2004). Katz and Postal (1964) treat negative-question as a single feature, not a combination of the negative and the question.

In papers on negative polar questions in English, starting with (Ladd 1981) two types of NPQs are distinguished: with 'inside negation' reading or 'outside negation' reading. ON-NPQs have the same meaning as PPQs, the speaker wants a confirmation of positive proposition $\mathrm{P}$ (You guys might be starving. You want to get something to eat? - Yeah, isn't there a vegetarian restaurant around here?). These questions are relevant only when there is no evidence against P. INNPQs are used for confirmation of negative proposition -P and are relevant when there is a contextual evidence against $\mathrm{P}$ (There's not really any place to go in Hyde Park - Oh, really, isn't there a vegetarian restaurant around here?). It is possible to use the same terminology with Russian NPQs ${ }^{1}$. In this paper, only the ONNPQs are considered.

NPQs also differ by the syntactic position of negation. Roelofsen et al. (2012) distinguishes low negation polar questions (Did Lucy not go to Greece?) and high negation polar questions with a negative clitic attached to the inverted

ExLing 2020: Proceedings of $11^{\text {th }}$ International Conference of Experimental Linguistics, 12-14 October 2020, Athens, Greece 
154 Y. Panchenko

auxiliary (Didn't Lucy go to Greece?). In Russian, ne-questions (with the basic negative particle ne only) and ne-li-questions (with ne particle in combination with li particle and reversed word order) are quite similar to high and low NPQs. They slightly differ in thema-rhematic relations (Shatunovskii 2005) but often are interchangeable.

Negative polar questions might use a different response system from the positive ones. Evgrafova (1984) identifies two strategies for answering NPQs: (1) situational oriented - the yes-answer corresponds to a positive situation, the no-answer corresponds to a negative one; (2) communicative oriented - yesanswer corresponds to confirmation, no-answer corresponds to contradiction (some languages use special contradictional answers such as german doch or french si). The acceptance of short answers without the predicate repetition differs from one language to another. Languages can stick with one strategy or mix the both strategies in different ways:

3. English:

- Isn't it beautiful?

- No, it isn't. / Yes, it is.

4. Italian:

- Non hai fame? 'Aren't you hungry?'

- No, non bo fame. 'No, I'm not.' / No, ho fame. 'No, I am.'

5. Russian (colloquial):

- Vy ne pomnite svoyu pervuyu knigu? 'Don't you remember your first book?'

- Net, ne pomnyu. 'No, I don't remember.' / Net, pomnyu. 'No, I remember.' /

Da, ne pomnyu. 'Yes, I don't remember.' / Da, pomnyu. 'Yes, I remember.'

As you can see, colloquial Russian allows to use any strategy for confirmation and negation (while the response system of standart language is closer to Italian).

\section{Methodology}

The aim of this paper is to analyze generation, processing and acceptability judgment of answers to negative polar questions in Russian depending on the way of expressing negation in a question (ne- and ne-li questions, negative predicatives and pronouns) with an acceptability judgment experiment.

\section{Participants}

The experiment was performed on 100 adult native Russian speakers (mean age 20.21, range 18-36). 


\section{Materials}

Experimental materials included 20 Russian ON-NPQs, each one with 3 possible answers (response particle + predicate repetition): yes-agreement (negative confirmation: 'Yes, I don't remember), yes-denial and no-denial (positive contradiction: 'Yes, I do remember' or 'No, I do remember').

There were four types of questions: (1) NPQs with the basic negative particle, the ne-questions; (2) NPQs with negative predicatives (net, absence predicative; nel'sya 'impossible' etc.); (3) NPQs with negative pronouns or pronominal words; (4) NPQs containing the $l i$ particle, ne-li-questions.

\section{Procedure}

Participants were asked to evaluate each answer in terms of its grammatical acceptability using a Likert scale $1-5$. Also, for each question they were asked to choose the most possible meaning of a short 'yes' answer (confirmation or contradiction).

\section{Results}

The results approved the hypothesis that ne- and ne-li-questions differ in their response systems. Meanwhile, the way of expressing negation in ne-questions doesn't matter. Acceptability judgments correspond with the short answer comprehension: in ne-questions the yes-agreement answer has a higher score on the acceptability and the preferred meaning is agreement, while in ne-liquestions the situation is reversed.

Table 1. Acceptability judgment task results.

\begin{tabular}{|l|l|l|l|l|}
\hline & yes-agreement & yes-denial & no-denial & short yes meaning \\
\hline ne-questions & 3.84 & 3.03 & 3.64 & agreement \\
\hline negative predicatives & 4.21 & 2.23 & 4.12 & agreement \\
\hline negative pronouns & 3.85 & 2.49 & 3.4 & agreement \\
\hline ne-li-questions & 2.54 & 4.18 & 2.69 & denial \\
\hline
\end{tabular}

\section{Discussion}

According to the results, the response system for NPQs in colloquial Russian is freer than in the standard literary Russian language: situational and communicative oriented strategies are equally possible to use. It is interesting to compare response systems in colloquial and standart variants of other languages; for example, in English the situation seems very common, but it needs an experimental approval. 


\section{Notes}

1. In Russian works these two types of NPQs have different names: questions with inherent or non-inherent thema (Baranov, Kobozeva 1983), interpretive or noninterpretive questions (Stepanova 1992, Dobrushina 2014), "negative" or "positive" negative polar questions (Shatunovskii 1980). These terms are equal to IN- and ONNPQs.

\section{References}

Büring, D., Gungloson, C. 2000. Aren't positive and negative polar questions the same? California, UCSC/UCLA.

Dobrushina, E. R. 2014. What does the word net 'no' mean? In Dobrushina, E.R. 2014 Korpusnye issledovaniya po morfemnoi, grammaticheskoi i leksicheskoi semantike russkogo yazyka, 142-198. Moscow, PSTGU.

Evgrafova, S. M. On the issue of the affirmation and negation opposition. In Podlesskaya, V. I. (ed.), Lingvisticheskie issledovaniya: Tipologiya. Dialektologiya. Ehtimologiya. Komparativistika. Collected papers. Part 1, 97-107, Moscow, Nauka.

Katz, J. J., Postal, P. M. 1964. An integrated theory of linguistic descriptions. Cambridge, MIT Press.

Ladd, R. D. 1981. A first look at the Semantics and Pragmatics of Negative Questions and Tag Questions. Proceedings of Chicago Linguistic Society 17, 164-171.

Roelofsen, F., Venhuizen, N., Weidmann, S. 2012. Positive and negative polar questions in discourse. In Chemla E., Homer V., Winterstein G. (eds.) 2012 Proceedings of Sinn und Bedeutung 17, 455-472. Paris, ENS.

Romero, M., Han. C.-H. 2004. On negative yes/no questions. Linguistics and Philosophy 27(5), 609-658.

Savin, H. B., Perchonock, E. 1965 Grammatical structure and the immediate recall of English sentences. Journal of Verbal Learning and Verbal Behaviour 4(5), 348-353.

Shatunovskii, I. B. 2005. The main cognitive-communicative types of general questions in Russian. In Dialog: Komp'yuternaya lingvistika i intellektual'nye tekhnologii, 502 506, Moscow, Nauka.

Stepanova, E. B. 1992. Ne-particle in polar questions: meaning and scope. In Sistemnye semanticheskie svyazi yazykovykh edinits, 54-62, Moscow, MSU.

van Rooij, R., Šafářová, M. 2003. On polar questions. In Young R. B., Zhou Y. (eds.) 2003 Proceedings of Semantics and Linguistics Theory (SALT 13), 292-309. USA, CLC Publications. 